\title{
Developmental Trends in the Energy Cost of Physical Activities Performed by Youth
}

\author{
Stewart G. Trost, Christopher C. Drovandi, and Karin Pfeiffer
}

\begin{abstract}
Background: Published energy cost data for children and adolescents are lacking. The purpose of this study was to measure and describe developmental trends in the energy cost of 12 physical activities commonly performed by youth. Methods: A mixed age cohort of 209 participants completed 12 standardized activity trials on 4 occasions over a 3-year period (baseline, 12-months, 24-months, and 36-months) while wearing a portable indirect calorimeter. Bayesian hierarchical regression was used to link growth curves from each age cohort into a single curve describing developmental trends in energy cost from age 6 to 18 years. Results: For sedentary and light-intensity household chores, YOUTH METs (METy) remained stable or declined with age. In contrast, METy values associated with brisk walking, running, basketball, and dance increased with age. Conclusions: The reported energy costs for specific activities will contribute to efforts to update and expand the youth compendium.
\end{abstract}

Keywords: exercise, absolute intensity, measurement, children, adolescents

Quantifying the absolute intensity or energy cost of movement is essential for the accurate prediction of daily energy requirements and an important goal in many physical activity studies involving children and adolescents. ${ }^{1}$ Validated direct and indirect measures of activity-related energy expenditure are available $;{ }^{2}$ however, because they require sophisticated instrumentation and limit the type of activities that can be measured, they are impractical to implement in large population-based studies and/or field-based research. ${ }^{1,2}$ For this reason, energy cost is commonly estimated from self-report or observational data using published tables or compendia of energy cost values.

The Compendium of Physical Activities provides empiricallybased energy cost estimates (METs) for more than 600 specific activities from 21 activity categories. ${ }^{3-5}$ However, because the energy cost estimates are based on studies of healthy adults, they are not valid for use in children and adolescents. To address this limitation, Ridley and colleagues ${ }^{6}$ developed the Compendium of Energy Expenditures in Youth. However, due to the lack of published energy cost data for children and adolescents, $65 \%$ of the values listed were estimated from the adult Compendium.

As a contribution to ongoing efforts to update and extend the Youth Compendium, the purpose of this study was to quantify the energy cost of 12 commonly performed physical activities in an age-diverse cohort of children and adolescents. Implementing an accelerated longitudinal study design, ${ }^{7}$ we also describe sex-specific developmental trends in the energy cost of each activity from age 6 to 18 years.

Trost (s.trost@qut.edu.au) is with the School of Exercise and Nutrition Science, Institute of Health and Biomedical Innovation at QLD Centre for Children's Health Research; Drovandi is with the Science and Engineering Faculty, School of Mathematical and Statistical Science; Queensland University of Technology, Australia. Pfeiffer is with the Dept of Kinesiology, Michigan State University.

\section{Methods}

In total, 209 children and adolescents (51.7\% Male, 86.1\% White, non-Hispanic) participated in the study. Descriptive characteristics for the baseline sample are presented in Table 1. Before participation, parental written consent and child assent were obtained. The study was approved by the institutional review boards of Oregon State and Michigan State University.

Table 1 Participants' Characteristics at Baseline ( $n=209)$

\begin{tabular}{lc}
\hline Characteristic & Mean \pm SD \\
\hline Age $(\mathrm{yr})$ & $11.0 \pm 2.7$ \\
Height $(\mathrm{cm})$ & $146.9 \pm 16.6$ \\
Body mass $(\mathrm{kg})$ & $43.7 \pm 17.3$ \\
BMI percentile & $61.7 \pm 28.3$ \\
\hline Age cohort distribution & $\mathbf{( N ,} \%)$ \\
\hline $6 \mathrm{yr}$ & $8,3.8 \%$ \\
$7 \mathrm{yr}$ & $20,9.6 \%$ \\
$8 \mathrm{yr}$ & $15,7.2 \%$ \\
$9 \mathrm{yr}$ & $22,10.5 \%$ \\
$10 \mathrm{yr}$ & $24,11.5 \%$ \\
$11 \mathrm{yr}$ & $24,11.5 \%$ \\
$12 \mathrm{yr}$ & $24,11.5 \%$ \\
$13 \mathrm{yr}$ & $29,13.9 \%$ \\
$14 \mathrm{yr}$ & $26,12.4 \%$ \\
$15 \mathrm{yr}$ & $9,4.3 \%$ \\
$16 \mathrm{yr}$ & $8,3.8 \%$ \\
$\% \mathrm{male}$ & $51.0 \%$ \\
$\% \mathrm{obese} / \mathrm{overweight}$ & $26.2 \%$ \\
\hline
\end{tabular}




\section{Study Protocol}

Participants performed 12 standardized activity trials on 4 occasions over a 3-year period (baseline, 12-month, 24-month, and 36-month follow-up). The trials were completed over 2 laboratory visits scheduled within a 2 -week time period. On visit 1 , participants completed the following 6 trials: lying down, hand writing, laundry task, throw and catch, comfortable over-ground walk, and aerobic dance. On visit 2, participants completed the remaining 6 trials: computer game, floor sweeping, brisk over-ground walk, basketball, over-ground run/jog, and brisk treadmill walk. Each activity trial lasted 5 min with the exception of the lying down trial, which lasted $10 \mathrm{~min}$. To ensure even pacing during the over ground walking and running trials, a research assistant walked/jogged alongside each participant. Verbal feedback was provided if the research assistant felt that the pace was inappropriate. The walking speed during the treadmill walk was set to equal the walking speed achieved during the brisk over ground walking trial. Self-selected walking and running speeds were established at baseline and replicated at 12-, 24-, and 36-months follow-up. A detailed description of the activity trials can be found elsewhere. ${ }^{8}$

\section{Instrumentation}

Oxygen uptake $\left(\mathrm{VO}_{2}\right)$ during each activity was measured breathby-breath and averaged every $10 \mathrm{sec}$ using the Oxycon Mobile (Yorba Linda, CA), a light weight portable indirect calorimetry system. Before each test, the Oxycon unit was calibrated according to manufacturer's guidelines. Flow control and gas calibration was performed using Oxycon's automated calibration system, with the $\mathrm{CO}_{2}$ and $\mathrm{O}_{2}$ analyzers calibrated against room air as well as to a reference gas of known composition $\left(4 \% \mathrm{CO}_{2}\right.$ and $\left.16 \% \mathrm{O}_{2}\right)$. The Oxycon Mobile has been shown to provide valid measures of oxygen uptake over a range of exercise intensities. ${ }^{9}$

\section{Data Treatment}

Customized software was used to calculate mean $\mathrm{VO}_{2}$ recorded between minutes 2.5 and 4.5 of each activity trial. For the lying down trial, $\mathrm{VO}_{2}$ was calculated from data collected between minutes 7.0 and 9.0. For each participant, the attainment of steady state was confirmed by inspection of recorded HR and $\mathrm{VO}_{2}$ values. Tolerance levels were $\pm 5 \mathrm{bpm}$ and $\pm 10 \%$ for $\mathrm{HR}$ and $\mathrm{VO}_{2}$, respectively. YOUTH METs (METy) were calculated by dividing mean weight relative $\mathrm{VO}_{2}$ by resting energy expenditure (REE). ${ }^{10}$ REE was predicted from the participant's sex, age, body mass, and height using Schofield's equation for children aged 3-10 or $10-18$ years. ${ }^{11}$

\section{Statistical Analyses}

Descriptive statistics (Mean, SD, and Range) for activity-specific $\mathrm{VO}_{2}$ and MET values, measured at baseline, were calculated across the entire sample and groups defined by age. To describe developmental trends in energy cost between the ages of 6 and 18 years, a Bayesian framework was employed to model energy cost (Youth METs), measured at baseline, 12-, 24-, and 36-months follow-up, as a quadratic function of age, with activity type and gender included as factor variables. Interaction terms between all variables were included, allowing for a different quadratic relationship for each activity and gender combination. To account for the correlation between repeated observations from the same individual, the model included a random intercept term in the mean for each individual. Markov chain Monte Carlo procedures were then used to estimate the expected MET value and $95 \%$ credibility interval for each age value within the age range of the data for every combination of activity type and gender. The Bayesian model was implemented using the "rjags" package in the R statistical software package.

\section{Results}

Table 2 displays the energy cost estimates for the 12 activities measured at baseline. Applying conventional MET-based definitions of intensity, lying down and playing computer games were considered sedentary ( $\leq 1.5$ METs); hand writing while seated, throwing and catching, folding laundry, sweeping the floor, dancing, and comfortable-paced walking were considered lightintensity PA ( $\geq 1.5$ and $<4$ METs.); walking briskly over ground or on a treadmill were considered moderate-intensity PA $(\geq 4$ and $<6$ METs); while playing basketball or running were considered vigorous-intensity PA ( $\geq 6$ METs). There was, however, substantial individual variability in the energy cost of each activity, and many of the activities were completed at an absolute intensity ranging from light to vigorous.

Based on cross-sectional baseline data, weight-relative $\mathrm{VO}_{2}$ for each activity declined with age. For the sedentary and low-tomoderate intensity activities (lying down, computer game play, seated hand writing, throwing and catching, folding laundry, floor sweeping, and comfortable-paced walk) METy remained relatively stable across 4 age groups. However, for the remaining moderateto-vigorous activities (aerobic dance, brisk walking over ground, brisk treadmill walking, playing basketball, and running), METy tended to increase with age.

Figure 1 displays the developmental trends in energy cost (METy and 95\% credibility interval) for all 12 activities estimated from the accelerated longitudinal analysis. Separate curves were generated for boys and girls; however, no significant sex differences were observed. For lying down, seated hand writing, computer game play, folding laundry, throwing and catching, floor sweeping, and comfortable-paced walking, METy remained stable or declined marginally between the ages 6 and 18. For aerobic dancing, brisk walking, and running, METy increased with age, with running exhibiting a steep age-related increase in absolute energy cost. The energy cost of basketball exhibited a modest curvilinear relationship with age. In general, the activity-specific METy estimates derived from the longitudinal data were commensurate with those obtained in cross-sectional analyses.

\section{Discussion}

The current study reports measured energy cost values (weight relative $\mathrm{VO}_{2}$ and METy) for 12 physical activities commonly performed by children and adolescents. Activities ranged from sedentary to vigorous, and represented a number of domains or activity categories included in the original Youth Compendium, including sedentary behavior, transport, play/sport, school work, and chores. The resultant estimates will contribute to ongoing efforts to update and expand the Compendium of Energy Expenditure for Youth. ${ }^{6}$

A unique aspect of this study was the use of an accelerated longitudinal study design to model sex specific developmental trends in energy cost. Accelerated longitudinal designs are designs in which adjacent segments of longitudinal data on a specific age cohort 
Table 2 Descriptive Statistics for Baseline $\mathrm{VO}_{2}$ and METy

\begin{tabular}{|c|c|c|c|c|c|c|c|}
\hline \multirow[b]{2}{*}{ Activity } & \multirow[b]{2}{*}{$\mathbf{N}^{*}$} & \multicolumn{3}{|c|}{$\mathrm{VO}_{2}\left(\mathrm{~mL} \cdot \mathrm{kg}^{-1} \cdot \mathrm{min}^{-1}\right)$} & \multicolumn{3}{|c|}{ METy } \\
\hline & & Mean & SD & Range & Mean & SD & Range \\
\hline Resting $\mathrm{EE}^{\mathrm{a}}$ & 209 & & & & & & \\
\hline Lying down & 198 & 6.0 & 1.6 & $3.5-10.9$ & 1.3 & 0.2 & $1.0-1.9$ \\
\hline Computer game & 198 & 7.0 & 1.7 & $4.0-12.6$ & 1.5 & 0.2 & $1.0-2.5$ \\
\hline Hand writing & 203 & 7.3 & 2.0 & $3.6-13.4$ & 1.6 & 0.3 & $0.9-3.0$ \\
\hline Throw and catch & 203 & 12.6 & 3.9 & $5.3-28.2$ & 2.7 & 0.5 & $1.6-5.2$ \\
\hline Laundry task & 202 & 13.5 & 3.7 & $6.4-25.0$ & 2.9 & 0.5 & $1.7-4.7$ \\
\hline Sweeping & 204 & 15.7 & 4.6 & $7.5-32.6$ & 3.4 & 0.6 & $1.9-5.4$ \\
\hline Aerobic dance & 204 & 17.6 & 4.0 & $8.3-35.5$ & 3.9 & 0.9 & $1.5-7.0$ \\
\hline Comfortable walk & 198 & 17.7 & 3.9 & $10.2-30.8$ & 3.8 & 0.6 & $2.5-5.8$ \\
\hline Brisk walk & 203 & 22.0 & 4.5 & $11.0-34.3$ & 4.8 & 0.8 & $2.7-7.7$ \\
\hline Treadmill walk & 200 & 23.7 & 4.5 & $12.5-34.5$ & 5.2 & 0.9 & $3.4-8.5$ \\
\hline Basketball & 200 & 32.9 & 7.9 & $16.0-59.8$ & 7.2 & 1.6 & $4.1-14.4$ \\
\hline Run & 200 & 39.9 & 7.0 & $21.0-58.1$ & 8.9 & 1.7 & $4.5-15.5$ \\
\hline \multicolumn{8}{|c|}{ Age: $6-8$ years $(N=43$, Mean age $=7.2 \pm 0.8 y)$} \\
\hline Resting EE ${ }^{a}$ & 43 & 5.9 & 0.7 & $4.1-7.6$ & - & - & - \\
\hline Lying down & 40 & 7.3 & 1.7 & $4.4-10.9$ & 1.2 & 0.2 & $1.0-1.8$ \\
\hline Computer game & 39 & 8.5 & 1.5 & $5.7-12.6$ & 1.5 & 0.2 & $1.1-1.9$ \\
\hline Hand writing & 41 & 9.2 & 2.0 & $4.3-13.4$ & 1.6 & 0.3 & $1.1-2.2$ \\
\hline Throw and catch & 42 & 15.8 & 4.4 & $7.0-28.2$ & 2.7 & 0.6 & $1.7-4.3$ \\
\hline Laundry task & 40 & 16.6 & 4.0 & $6.9-25.1$ & 2.9 & 0.6 & $1.7-4.5$ \\
\hline Sweeping & 42 & 20.5 & 5.0 & $7.5-32.6$ & 3.5 & 0.7 & $1.9-5.4$ \\
\hline Aerobic dance & 42 & 18.2 & 4.7 & $8.5-29.2$ & 3.3 & 0.7 & $2.2-5.1$ \\
\hline Comfortable walk & 41 & 20.7 & 4.0 & $14.4-29.9$ & 3.7 & 0.5 & $2.6-4.6$ \\
\hline Brisk walk & 42 & 25.6 & 4.3 & $11.3-34.3$ & 4.5 & 0.7 & $2.8-6.2$ \\
\hline Treadmill walk & 41 & 26.8 & 4.3 & $13.5-33.1$ & 4.8 & 0.7 & $3.4-6.3$ \\
\hline Basketball & 41 & 35.7 & 7.5 & $21.0-59.8$ & 6.2 & 1.2 & $4.1-9.7$ \\
\hline Run & 39 & 42.3 & 6.7 & $20.9-53.6$ & 7.5 & 1.0 & $4.7-9.5$ \\
\hline \multicolumn{8}{|c|}{ Age: $9-10$ years $(\mathrm{N}=46$, Mean Age $=9.4 \pm 0.6$ y) } \\
\hline Resting EE $\mathrm{EE}^{\mathrm{a}}$ & 46 & 5.1 & 0.6 & $3.4-6.3$ & - & - & - \\
\hline Lying down & 45 & 6.3 & 1.3 & $3.6-9.2$ & 1.3 & 0.2 & $1.0-1.8$ \\
\hline Computer game & 46 & 7.5 & 1.7 & $4.2-12.4$ & 1.5 & 0.3 & $1.1-2.5$ \\
\hline Hand writing & 45 & 7.7 & 1.7 & $4.1-13.1$ & 1.6 & 0.3 & $0.9-2.6$ \\
\hline Throw and catch & 45 & 13.8 & 3.4 & $7.1-27.6$ & 2.7 & 0.4 & $1.8-3.7$ \\
\hline Laundry task & 45 & 15.0 & 3.2 & $8.2-23.8$ & 3.1 & 0.5 & $1.8-4.7$ \\
\hline Sweeping & 46 & 16.9 & 3.2 & $9.5-24.9$ & 3.4 & 0.6 & $2.5-5.0$ \\
\hline Aerobic dance & 44 & 18.6 & 4.7 & $8.3-35.5$ & 3.8 & 1.0 & $1.6-7.0$ \\
\hline Comfortable walk & 44 & 18.9 & 3.6 & $11.8-30.8$ & 3.9 & 0.6 & $2.8-5.9$ \\
\hline Brisk walk & 45 & 23.6 & 3.5 & $16.5-30.8$ & 4.8 & 0.6 & $3.5-6.2$ \\
\hline Treadmill walk & 46 & 24.9 & 3.8 & $17.2-34.5$ & 5.1 & 0.7 & $3.9-6.9$ \\
\hline Basketball & 46 & 34.6 & 7.7 & $17.6-52.5$ & 7.0 & 1.3 & $4.7-10.6$ \\
\hline Run & 46 & 40.6 & 6.5 & $26.3-55.6$ & 8.3 & 1.3 & $\begin{array}{l}5.2-10.7 \\
\text { (continu }\end{array}$ \\
\hline
\end{tabular}


Table 2 (continued)

\begin{tabular}{|c|c|c|c|c|c|c|c|}
\hline \multirow[b]{2}{*}{ Activity } & \multirow[b]{2}{*}{$\mathbf{N}^{*}$} & \multicolumn{3}{|c|}{$\mathrm{VO}_{2}\left(\mathrm{~mL} \cdot \mathrm{kg}^{-1} \cdot \mathrm{min}^{-1}\right)$} & \multicolumn{3}{|c|}{ METy } \\
\hline & & Mean & SD & Range & Mean & SD & Range \\
\hline \multicolumn{8}{|c|}{ Age: $11-12$ years $(\mathrm{N}=48$, Mean Age $=11.4 \pm 0.6 \mathrm{y})$} \\
\hline Resting EE ${ }^{a}$ & 48 & 4.6 & 0.7 & $2.9-6.1$ & - & - & - \\
\hline Lying down & 46 & 5.8 & 1.5 & $3.5-9.9$ & 1.3 & 0.2 & $1.0-1.9$ \\
\hline Computer game & 45 & 6.5 & 1.6 & $4.3-9.9$ & 1.4 & 0.2 & $1.0-1.8$ \\
\hline Hand writing & 46 & 6.8 & 1.6 & $4.0-12.4$ & 1.5 & 0.3 & $1.1-3.0$ \\
\hline Throw and catch & 46 & 12.1 & 3.0 & $6.4-19.0$ & 2.6 & 0.5 & $1.9-3.7$ \\
\hline Laundry task & 46 & 12.8 & 3.3 & $6.4-23.4$ & 2.9 & 0.5 & $1.8-4.4$ \\
\hline Sweeping & 46 & 14.9 & 3.4 & $7.5-22.5$ & 3.3 & 0.5 & $2.1-4.9$ \\
\hline Aerobic dance & 47 & 18.0 & 3.4 & $10.6-27.7$ & 4.1 & 0.7 & $2.7-6.1$ \\
\hline Comfortable walk & 46 & 17.2 & 3.1 & $10.7-22.5$ & 3.9 & 0.6 & $2.8-5.5$ \\
\hline Brisk walk & 46 & 20.9 & 3.1 & $14.7-27.4$ & 4.7 & 0.6 & $3.5-6.9$ \\
\hline Treadmill walk & 45 & 22.7 & 3.3 & $14.9-28.6$ & 5.1 & 0.8 & $4.0-7.7$ \\
\hline Basketball & 45 & 32.4 & 6.8 & $17.8-46.7$ & 7.2 & 1.1 & $5.1-9.6$ \\
\hline Run & 46 & 38.8 & 6.4 & $24.7-58.1$ & 8.7 & 1.1 & $6.9-11.5$ \\
\hline \multicolumn{8}{|c|}{ Age: $13-16$ years $(N=72$, Mean Age $=13.9 \pm 1.0 y)$} \\
\hline Resting EE & 72 & 4.0 & 0.5 & $2.8-5.8$ & - & - & - \\
\hline Lying down & 67 & 5.0 & 0.9 & $3.6-7.4$ & 1.3 & 0.2 & $1.0-1.9$ \\
\hline Computer game & 68 & 5.9 & 1.1 & $4.0-8.6$ & 1.5 & 0.2 & $1.1-1.9$ \\
\hline Hand writing & 71 & 6.1 & 1.4 & $3.2-9.4$ & 1.6 & 0.3 & $1.0-2.1$ \\
\hline Throw and catch & 70 & 10.2 & 2.4 & $5.3-19.1$ & 2.6 & 0.5 & $1.6-4.0$ \\
\hline Laundry task & 71 & 11.2 & 2.3 & $7.3-17.3$ & 2.9 & 0.4 & $2.0-4.0$ \\
\hline Sweeping & 70 & 12.6 & 2.8 & $7.5-21.6$ & 3.3 & 0.5 & $2.2-4.7$ \\
\hline Aerobic dance & 71 & 16.5 & 3.4 & $9.6-25.8$ & 4.3 & 0.8 & $2.9-6.2$ \\
\hline Comfortable walk & 67 & 15.4 & 2.8 & $10.2-21.7$ & 4.0 & 0.6 & $2.9-5.4$ \\
\hline Brisk walk & 70 & 19.6 & 4.3 & $11.0-30.9$ & 5.1 & 1.0 & $2.7-7.2$ \\
\hline Treadmill walk & 68 & 21.9 & 4.7 & $12.5-32.5$ & 5.7 & 1.1 & $3.6-8.5$ \\
\hline Basketball & 68 & 30.4 & 8.2 & $16.0-54.1$ & 7.8 & 1.7 & $4.4-11.6$ \\
\hline Run & 69 & 38.9 & 7.6 & $24.6-58.0$ & 10.2 & 1.7 & $6.6-15.5$ \\
\hline
\end{tabular}

Note. Data are reported for the entire sample and groups defined by age.

* Sample size for each activity varies due to missing data for $\mathrm{VO}_{2}$ due to equipment malfunction, failure to meet steady state criteria, or participant absent, failed to complete the entire trial, or did not follow instructions.

${ }^{a}$ Resting energy expenditure (EE) predicted from the participant's sex, age, body mass, and height using Schofield's equation for children aged 3-10 or 10-18 yr. ${ }^{9}$

are linked with other temporally related age cohorts to determine the existence of a common developmental trend over much longer periods. ${ }^{7}$ Through the implementation of Bayesian hierarchical modeling, we combined growth curves from each overlapping age cohort into a single curve describing developmental trends in energy cost over the entire age range. This analysis yielded a number of important insights with significant implications for future iterations of the Youth Compendium. First, expressed as METy, the energy cost of sedentary and low-intensity physical activities remained relatively stable during childhood and adolescence, suggesting that a single METy value could be assigned to activities of this type. Second, METy for activities dependent on motor performance and/ or motivation varied systematically with age. Within our cohort, METy values for household chores tended to decrease with age, while METy for sporting and fitness activities tended to increase with age. Although these observations require confirmation in other samples, our results confirm the need for age-group specific energy cost values for activities in these categories. Third, METy values for moderate-to-vigorous ambulatory activities such as brisk walking and running increased with age, despite the fact that self-selected walking and running speeds were held constant over the 4 measurement waves. Because resting energy expenditure and the energy cost of locomotion decrease with age differentially, the MET value for walking and running tends to increase. This finding supports the current practice of considering both the child's age and speed of locomotion when assigning METy values to walking and running. ${ }^{6}$ Fourth and finally, our study provided no consistent evidence of sex differences in METy values, thus precluding the need to list sex-specific energy cost values in future iterations of the compendium. 

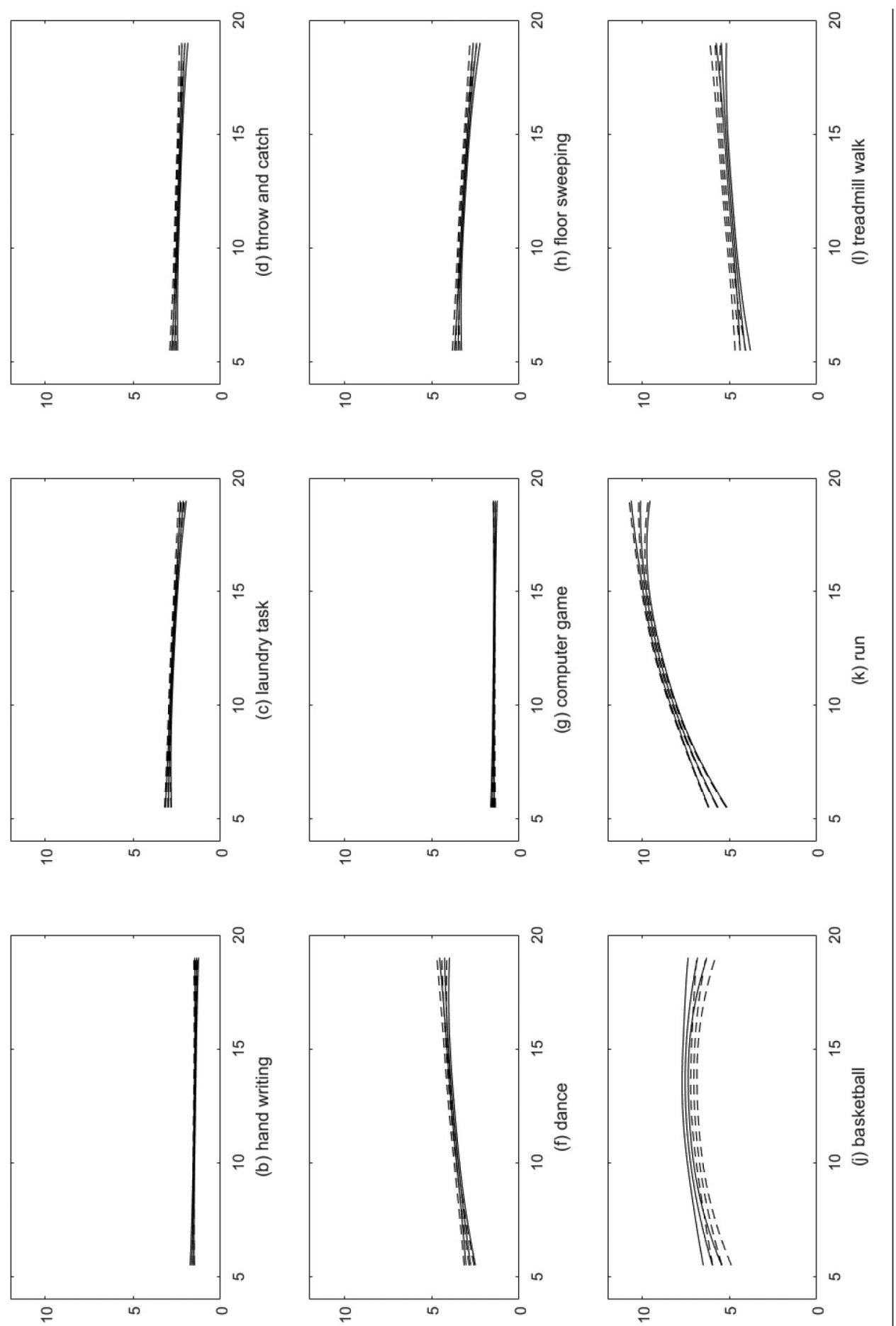

|
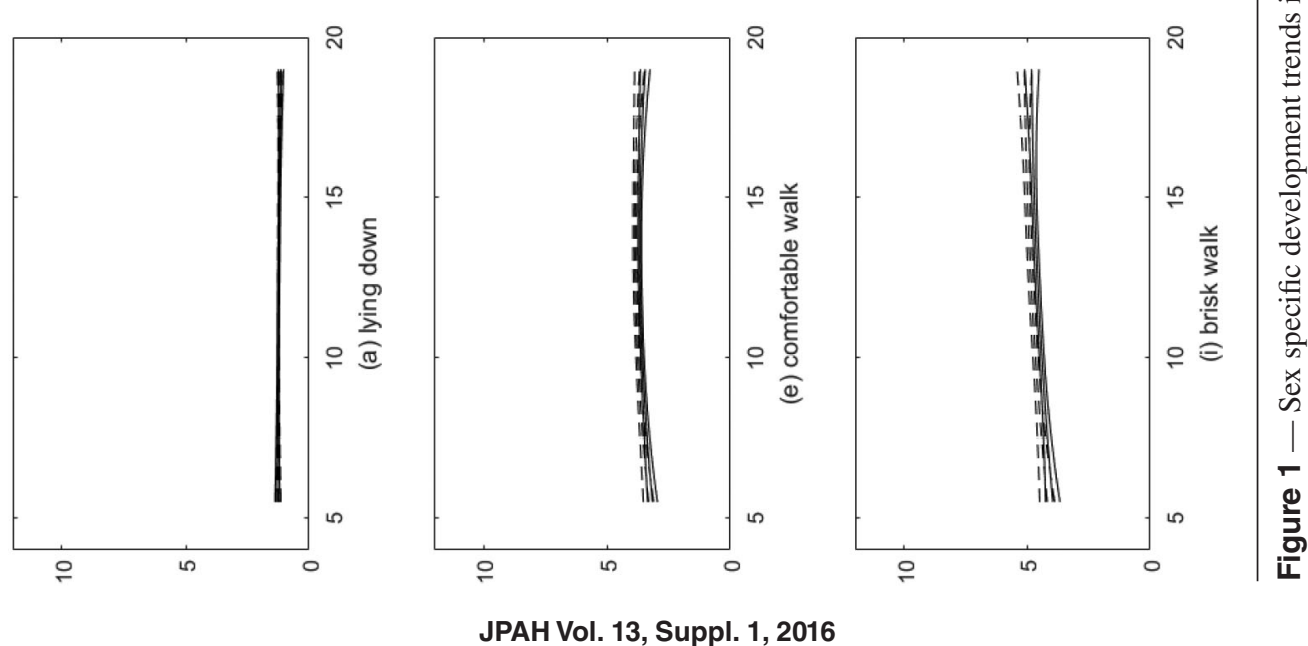


\section{Acknowledgments}

This study was supported by the NIH Grant R01 55400. CCD was supported by an Australian Research Council's Discovery Early Career Researcher Award funding scheme DE160100741.

\section{References}

1. Trost SG. Measurement of physical activity in children and adolescents. Am J Lifestyle Med. 2007;1:299-314. doi:10.1177/1559827607301686

2. LaMonte MJ, Ainsworth BE. Quantifying energy expenditure and physical activity in the context of dose response. Med Sci Sports Exerc. 2001;33(6, suppl):S370-S378. PubMed doi:10.1097/00005768200106001-00006

3. Ainsworth BE, Haskell WL, Leon AS, et al. Compendium of physical activities: classification of energy costs of human physical activities. Med Sci Sports Exerc. 1993;25:71-80. PubMed doi:10.1249/00005768-199301000-00011

4. Ainsworth BE, Haskell WL, Whitt MC, et al. Compendium of physical activities: an update of activity codes and MET intensities. Med Sci Sports Exerc. 2000;32(Suppl):S498-S516. PubMed doi:10.1097/00005768-200009001-00009

5. Ainsworth BE, Haskell WL, Herrmann SD, et al. 2011 Compendium of physical activities: a second update of codes and MET values.
Med Sci Sports Exerc. 2011;43(8):1575-1581. PubMed doi:10.1249/ MSS.0b013e31821ece12

6. Ridley K, Ainsworth BE, Olds TS. Development of a compendium of energy expenditures for youth. Int J Behav Nutr Phys Act. 2008;5:45. PubMed doi:10.1186/1479-5868-5-45

7. Bell RQ. Convergence: an accelerated longitudinal approach. Child Dev. 1953;24:145-152. PubMed doi:10.2307/1126345

8. Trost SG, Loprinzi PD, Moore R, Pfeiffer KA. Comparison of accelerometer cut-points for predicting activity intensity in youth. Med Sci Sports Exerc. 2011;43(7):1360-1368. PubMed doi:10.1249/ MSS.0b013e318206476e

9. Rosdahl H, Gullstrand L, Salier-Eriksson J, Johansson P, Schantz P. Evaluation of the Oxycon Mobile metabolic system against the Douglas bag method. Eur J Appl Physiol. 2010;109:159-171. PubMed doi:10.1007/s00421-009-1326-9

10. McMurray RG, Butte NF, Crouter SE, et al. Exploring metrics to express energy expenditure of physical activity in youth. PLoS One. 2015;10(6):e0130869 doi:10.1371/journal.pone.0130869. PubMed

11. Schofield WN. Predicting basal metabolic rate, new standards and review of previous work. Hum Nutr Clin Nutr. 1985;39(1, suppl):5-41. PubMed 